\title{
Study of the Effect of Ion implanation in Pre-vulcanized Natural rubber Latex
}

\author{
Najidha.S *,Haidy Ignatius ${ }^{* *}$, P.Predeep ${ }^{* * *}$ \\ *,Department of Physics, \\ BJM Government College, \\ Chavara,Kollam,Kerala,India.691583. \\ ** Post Graduate and Research Department of Physics,TKM College of Arts \\ and Science,Kollam,Kerala.691005 \\ ${ }^{* * * *}$ Laboratory for Molecular Electronics and Photonics \\ Department of Physics, \\ National Institute of Technology,Calicut,Kerala,India.673601 \\ DOI: 10.29322/IJSRP.11.05.2021.p11346 \\ http://dx.doi.org/10.29322/IJSRP.11.05.2021.p11346
}

\begin{abstract}
It has been reported that implant doping can create an insulator-semiconductor transition in Natural Rubber (cis 1, 4 polyisoprene), a member of the well-known butadiene family, in the unvulcanized state using $\mathrm{N}^{+}$ion. In this paper, we report, for the first time, the ion beam bombardment in Radiation Vulcanized Natural Rubber Latex (RVNRL) using $\mathrm{N}^{+}$ion with energy $60 \mathrm{keV}$ in the fluence range of $10^{14}$ to $10^{16} \mathrm{ions} / \mathrm{cm}^{2}$. The electrical conductivity shows about 10 orders of magnitude compared to the virgin state and is found to be increase with increasing fluence rate. Besides the UV/Vis and FTIR spectroscopic studies indicate the presence of new peaks with increase of fluence suggesting the formation of an ion beam induced conjugation in the polyisoprene backbone. A dramatic reduction in the optical band gap with the ion fluence, is also observed. The surface morphology of the implanted films has been studied by scanning electron microscopy and atomic force microscopy which indicate that the implantation of $\mathrm{N}^{+}$ions on polyisoprene surfaces introduces surface smoothening. Besides, an effort has been made to correlate the structural changes produced by both chemical and implant doping.
\end{abstract}

Index Terms- - Implantation, optical properties, radiation vulcanization, doping.

\section{INTRODUCTION}

Th introduction of ions into the surface of an elastomeric materials is an effective method for the synthesis and modification in the strycture, morphology and microstructure of the polymer surface. There is a dramatic evolution in the backbone structure of the virgin polymer takes place and this leads to graphite like material with enhanced chemical and physical properties. This wide range of changes in the structure and properties of polymers by implant doping could provide a great opportunity to modify polymer properties in a controlled manner by selecting suitable irradiation conditions [1],[2].

Although chemical doping can give very high levels of electrical conductivity, it has not usually proved to be easy to control the level of doping at the low levels needed for use in semiconductor devices. In addition, where doping is achieved by diffusion of the oxidizing or reducing agent in to the bulk polymer, the dopant mobility is then too high to allow long- term separation of regions of the sample with different dopant concentrations [3]. Therefore, there has been interest in the use of ion implantation to provide controlled doping levels. A number of earlier studies [2],[3] have shown that ion implantation increases the conductivity of the polymers; but the specific changes in the polymer relating to the increase in conductivity and the mechanisms of conduction are far from being well understood.

Natural Rubber is a unique material with versatile properties like high flexibility, excellent mechanical strength, processability, ozone resistance etc. Natural Rubber is made up of cis 1,4 polyisoprenoid units arranged in a highly stereoregular manner. Due to high structural regularity, natural rubber crystallizes on stretching and this strain-induced crystallization gives it the unique high tensile strength in unvulcanized states. It has been well established [4][5] that conjugated sequences of unsaturated double bonds can be introduced into polyisoprene backbone by doping with various halogens like $\mathrm{Cl}, \mathrm{Br}_{2}, \mathrm{I}_{2}$ and with lewis acids $\mathrm{SbCl}_{5}, \mathrm{SnCl}_{4}$ etc. $\mathrm{Even}$ though natural rubber in the unvulcanized states has high tensile strength, it is not suitable for many commercial applications. But vulcanization gives rubber its versatile properties, toughness and flexibility. It has been demonstrated [6],that pre-vulcanization of natural rubber latex will not hinder the formation of conjugated sequences, which is a pre-condition for developing intrinsic electrical conductivity in polymers.

Radiation Vulcanized Natural Rubber Latex (RVNRL) is a new addition to the range of raw materials available to the latex industry. In RVNRL, cross-linking of rubber molecules is brought about by gamma irradiation, as against sulphur crosslinking in conventional 
sulphur prevulcanised latex. RVNRL is most eco-friendly, as no chemicals, other than sensitizer and stabilizer are added. Due to its ingredient-free nature, the radiation vulcanization was chosen as a model for Natural Rubber Latex in this study. Prevulcanized Natural Rubber Latex is especially attractive for small -scale units since it can be used directly for the manufacture of latex products, thus eliminating the need for latex compounding other than the addition of antioxidant or pigment. In view of these aspects, a simple portrait on the impact of $\mathrm{N}^{+}$ions on the electrical and optical properties as well as the effect of chemical and implant doping of pre-vulcanized natural rubber latex is presented in this paper.

\section{EXPERIMENTAL}

The characteristics of the natural rubber latex which had been crosslinked by $\gamma$-radiation and the vulcanized conditions are given in table $1 \& 2$. Thin films of natural rubber latex were fabricated using spin coating technique on quartz substrates. Implantation was carried out at Indira Gandhi Centre for Atomic Research, Kalpakkam, India using a 150keV ion implanter (accelerator). The implantation was performed with $60 \mathrm{keV} \mathrm{N}^{+}$ion beam at room temperature. The beam current was kept at $0.3 \mu \mathrm{A}$ so as to avoid excessive heating of the target. The working pressure in the target chamber was about $10^{-6}$ Torr. The implantation doses were varied from $10^{14}$ to $10^{16}$ ions $/ \mathrm{cm}^{2}$. The implantation conditions are described in table 3. With fluences higher than $10^{14}$ ions $/ \mathrm{cm}^{2}$, it was found that the irradiated region becomes dense shiny black. The implanted films exhibit huge modifications of their surface properties and the appearance of conducting properties. Electrical conductivity measurements were performed at room temperature using a Keithly 2000 DMM and 6514 Electrometer by four probe and two-probe technique. The UV/Vis spectra of the implanted films were taken using a Cary $5000 \mathrm{UV}$-Vis Spectrophotometer. The FTIR spectroscopic measurements of the thin films were performed using a Nicolet Spectrometer in the range of $500-3000 \mathrm{~cm}^{-1}$. Information about the surface morphology were obtained using a Scanning Electron Microscopy and Atomic force microscopy. The scanning electron microscopy images of the surfaces of the implanted films were taken with JEOL 5600 model Scanning Electron Microscope. The atomic force microscopy has been taken using a scanning probe microscope from Digital Instrument USA with Nanoscope IV controller. The scan rate and scan lines per image are $1.969 \mathrm{~Hz}$ and 512, respectively. The evaluation of the roughness parameter of sample was based on scanned area of $1 \mu \mathrm{m} \times 1 \mu \mathrm{m}$. The mean square roughness (Rrms), defined as the mean value of the surface relative to the central plane for which the volume enclosed by the images above and below this plane are equal, was determined by using computer software.

\section{RESULT AND DISCUSSION}

Previous study [7] of ion beam modification of unvulcanized natural rubber indicated that with increasing irradiation fluence, ion irradiation results in a gradual change in the microstructure of natural rubber. A similar behaviour is observed in the case of radiation vulcanized natural rubber latex. The electrical conductivity of the implanted samples shows about 10 orders of magnitude compared to virgin polymer and is found to increase with increasing fluence. The coloration varies with increasing dose from a light brown for doses near $1 \times 10^{14}$ ions $/ \mathrm{cm}^{2}$ to a metallic black for doses greater than $1 \times 10^{16}$ ions $/ \mathrm{cm}^{2}$. The chemical doping of RVNRL indicated [6] a tenfold increase in electrical conductivity. But in the case of chemicfal doping the conduction is mainly due to the formation of charge transfer complexes that are produced by double bond shift reactions by a model proposed by L.Dai et al [8]. But the concept of charge transfer complexes is meaningless in implantation. The reports have shown [2],[3]that the primary phenomena associated with ion beam and polymer interactions are crosslinking, conjugation and degradation of the substrate occur leading to generation of broken bonds, formation of free radicals, double bonds, and charge carriers. Therefore, in the case of implanted RVNRL, it seems that the increase in conduction with fluence may be due to an increase in concentration of double bonds and hence increase in degree of conjugation in polymer films upon ion bombardment which could be attributed to the electronic energy transfer of the incident heavy ion which produces active chemical species free radicals along the polymer chain.

Table 1: Irradiation conditions used for vulcanization of latex

\begin{tabular}{|l|l|}
\hline Natural Rubber Latex & RVNRL \\
\hline Radiation Source & ${ }^{60} \mathrm{Co}, 7.38 \times 10^{15} \mathrm{~Bq}$ \\
\hline Irradiator & Rotating vessel system \\
\hline Rotating speed $\left(\mathrm{rev} \mathrm{min}^{-1}\right)$ & 10 \\
\hline Temperature $\left({ }^{0} \mathrm{C}\right)$ & 25 \\
\hline Dose rate $\left(\mathrm{kGy} \mathrm{h}^{-1}\right)$ & 0.565 \\
\hline Total dose $(\mathrm{kGy})$ & 12 \\
\hline
\end{tabular}

This publication is licensed under Creative Commons Attribution CC BY. 


\begin{tabular}{|l|l|}
\hline Sensitizer & a) 2-ethylhexyl acrylate 5phr \\
& b) $\mathrm{KOH} 0.3 \mathrm{phr}$ \\
\hline
\end{tabular}

Table 2: Characteristics of vulcanized natural rubber lattex used for this study

\begin{tabular}{|c|c|}
\hline Total Solid Content (TSC) & $55 \%$ \\
\hline Dry rubber Content (DRC & $53.8 \%$ \\
\hline Average molecular weight & $2.03 \times 10^{5}$ \\
\hline
\end{tabular}

Table 3: Experimental conditions used for ion implantation

\begin{tabular}{|l|l|}
\hline Chamber Pressure & $\sim 1 \times 10^{-6} \mathrm{mbar}$ \\
\hline Ion species & $\mathrm{N}^{+}$ \\
\hline Ion energy & $60 \mathrm{keV}$ \\
\hline Fluence & $1 \times 10^{14}$ to $1 \times 10^{16} \mathrm{ions} / \mathrm{cm}^{2}$ \\
\hline Beam Current & $0.3 \mu \mathrm{A}$ \\
\hline RF Plasma Power & $40 \mathrm{~W}$ \\
\hline Analyzer Current & $30 \mathrm{Amps}$ \\
\hline Suppresser Voltage & $40 \mathrm{~V}$ \\
\hline
\end{tabular}

The structural and chemical modifications of the polymer were investigated by spectroscopic analysis. The pristine film is transparent and colorless and shows no absorption peak in the visible region [6]. Fig. 1 depicts the optical absorption spectra of $\mathrm{N}^{+}$ion bombarded polyisoprene at different fluences. Increasing absorption at the shorter wavelengths, which also spreads towards the longer wavelength region with increasing doses, is a characteristic of a global conjugation increase in the polymer. The point to be noted is that in both the chemical doping and implantation, the absorption edge shifts towards longer wavelengths with the visually observed sample darkening. 


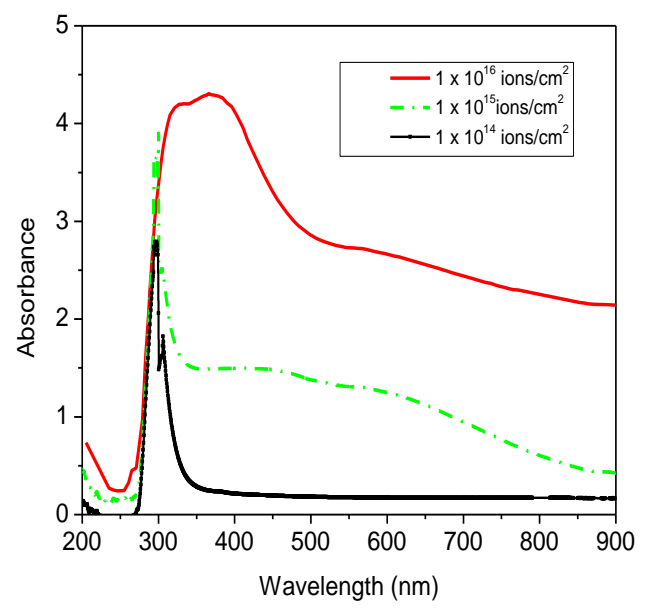

Figure 1: UV/Vis spectra of radiation vulcanized Natural Rubber latex at different fluences (a) at $10^{16}$ ions $/ \mathrm{cm}^{2}$, (b) at $10^{15}$ ions $/ \mathrm{cm}^{2},(\mathrm{c})$ at $10^{14}$ ions $/ \mathrm{cm}^{2}$.

The change in chemical structure of RVNRL due to ion implantation is identified by FTIR spectroscopy as in fig. 2 and fig 3 . The spectrum of pristine natural rubber latex had several peaks [6][9] which arise from $=\mathrm{CH}$ bending mode (at about $\left.765 \& 951 \mathrm{~cm}^{-1}\right), \mathrm{CH}_{2} \&$ $\mathrm{CH}_{3}$ stretching and deformation mode, stretching vibration of isolated $>\mathrm{C}=\mathrm{C}<$ bonds $\left(\right.$ at $1659.82 \mathrm{~cm}^{-1}$ ) etc. However, on irradiation, the intensity of $=\mathrm{CH}$ bending mode decreases considerably indicating the observed loss of flexibility through both chemical doping and implantation. This enhancement of sample rigidity at high fluence suggests that both chemical doping and implantation introduce an intra-polymer chain crosslinking leading to an evolution of structure. The main effect of implantation is expected to be the formation of free radicals. In this way, free radicals are produced on the polymer chain leading to the creation of double bonds. It can be seen that the implantation give rise to conjugated $\mathrm{C}=\mathrm{C}$ observed at $1545.88 \mathrm{~cm}^{-1}, 1648.78 \mathrm{~cm}^{-1}, 1650.40 \mathrm{~cm}^{-1}, 1619.17 \mathrm{~cm}^{-1}, 1539 \mathrm{~cm}^{-1}$ etc. At the same time the doping of RVNRL with iodine produces [6] new band appear at frequencies of $1643.6 \mathrm{~cm}^{-1}, 1632.9 \mathrm{~cm}^{-1}, 1617.5 \mathrm{~cm}^{-1}$ and still lower frequencies up to $1500 \mathrm{~cm}^{-1}$. The spectrum of the implanted films also indicate that as the dose increases the number of bands in the range 1000-17000 $\mathrm{cm}^{-1}$ increases. The presence of many new peaks with increase of fluence suggests the formation of conjugation as in the case of chemically doped samples. Also the peak at $1130 \mathrm{~cm}^{-1}$ corresponding to the bending vibration of $>\mathrm{CH}_{2}$ disappears. The peak at $1019 \mathrm{~cm}^{-1}$ and $974 \mathrm{~cm}^{-1}$ characteristics of $\mathrm{C}-\mathrm{H}$ out of plane stretching vibration of $=\mathrm{C}_{\mathrm{sp}}{ }^{2} \mathrm{H}-\mathrm{in}$ conjugated bond is formed which is also observed by L.Dai et al[5] on iodine doping of natural rubber. Moreover, the bands corresponding to the $\mathrm{CH}_{3}$ and $\mathrm{CH}_{2}$ stretching mode frequency does not get affected due to implantation, whatever the fluence is ie.,the nature and characteristic of this vibration do not change as in the case of chemically doped natural rubber latex [6]. Thus the spectral analysis of the implanted samples indicate the presence of conjugation along the carbon chain as observed in the case of chemical doping. Thus the increase in conductivity is consistent with the optical studies. 


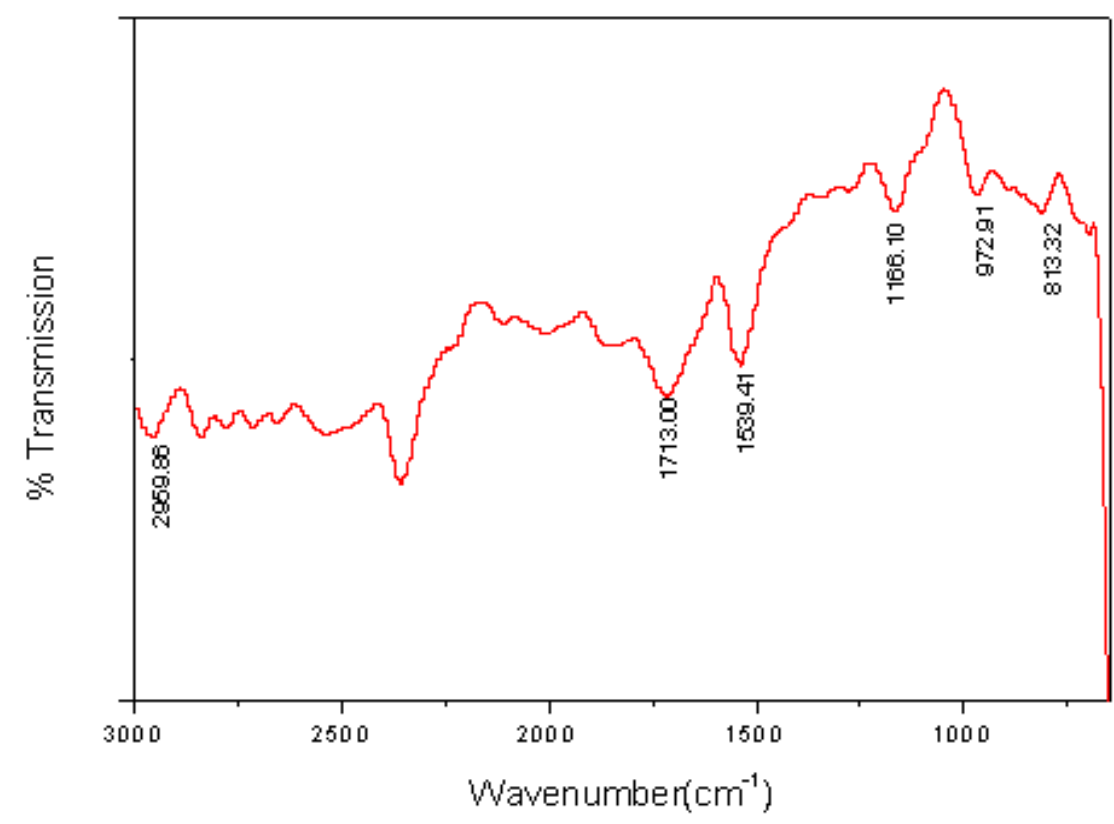

Figure 2: FTIR spectra of the implanted film at a fluence of $1 \times 10^{15} \mathrm{ions} / \mathrm{cm}^{2}$.

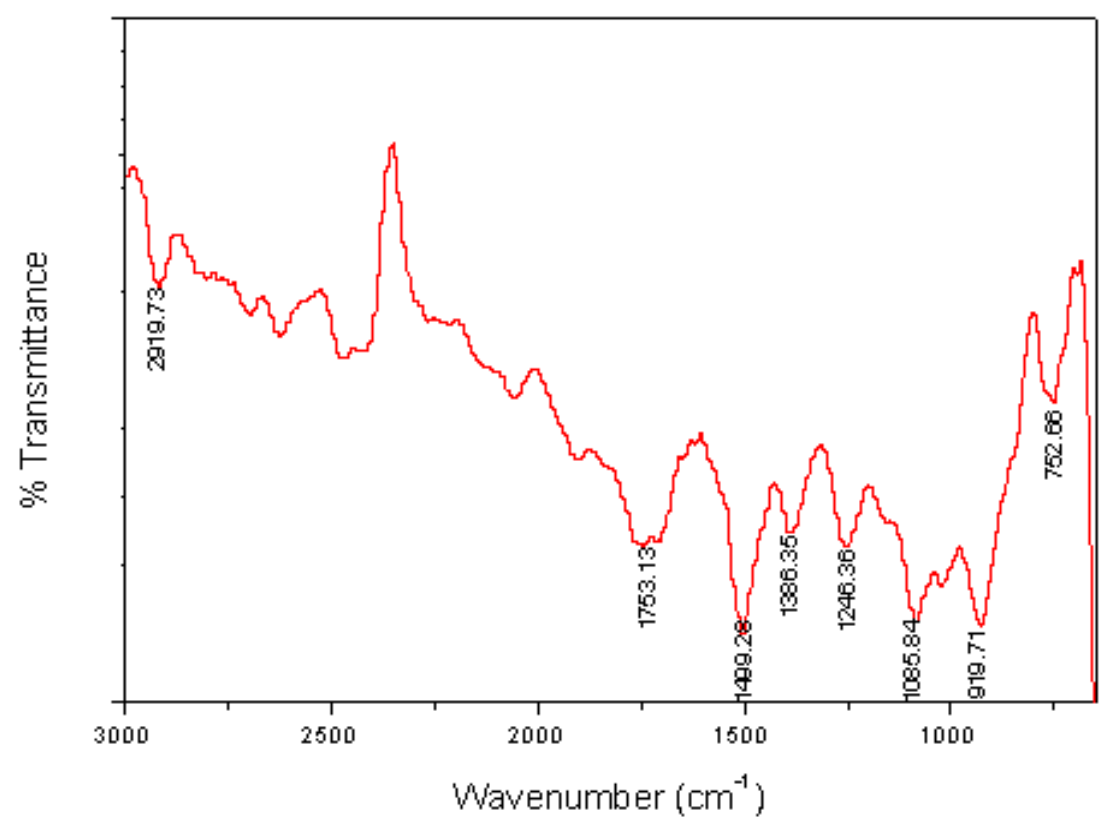

Figure 3: FTIR spectra of the implanted film at a fluence of $1 \times 10^{16}$ ions $/ \mathrm{cm}^{2}$ 


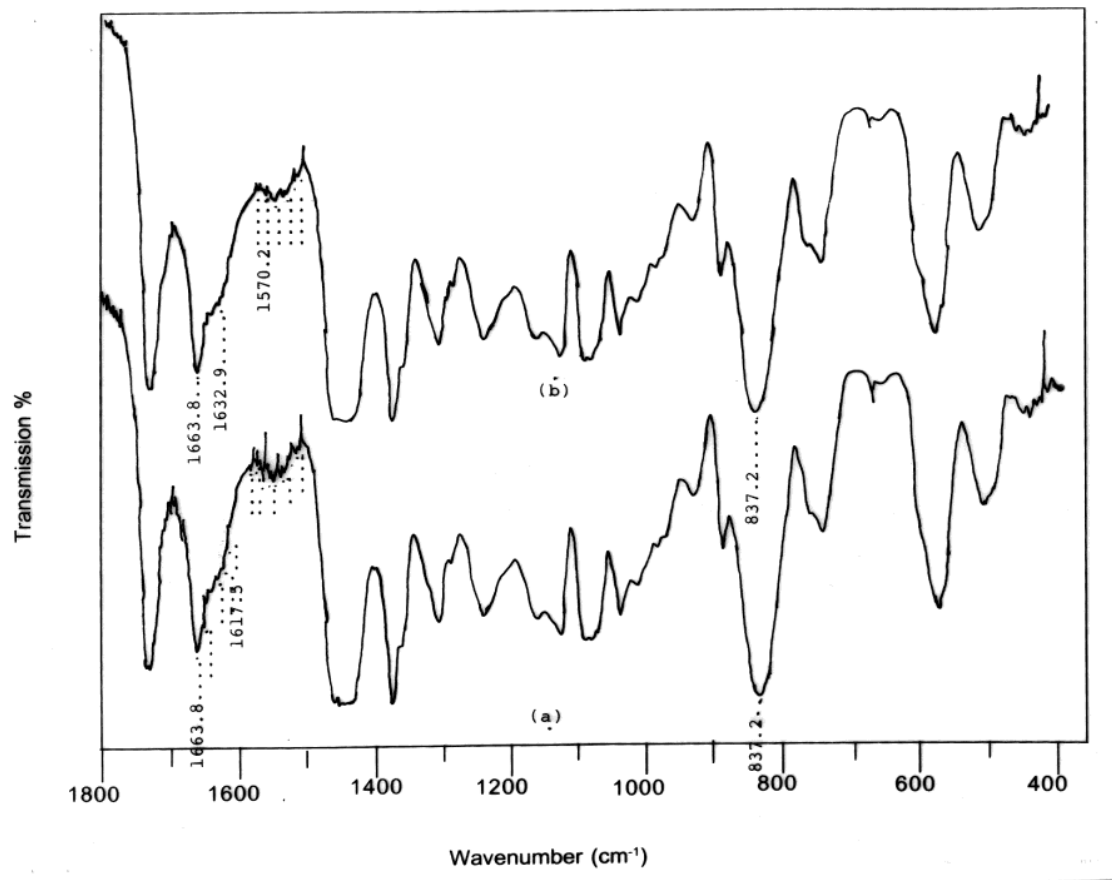

Figure 4: Fourier Transform Infra red Spectra (FTIR) of Radiation Vulcanized Natural Rubber Latex (vapour phase) doped films. (a) 72 $\mathrm{h}$ and (b) $96 \mathrm{~h}$.

The optical band gap $\left(E_{\mathrm{g}}\right)$ can be experimentally obtained from the absorption coefficient $(\alpha)$ measurement using the general relation of the type $\alpha h v=\mathrm{A}\left(\mathrm{h} v-\mathrm{E}_{\mathrm{g}}\right)^{\mathrm{n}}$ Where $\mathrm{A}$ is a constant, hu is the incident photon energy, $\mathrm{n}$ depends on the nature of the band transition; $\mathrm{n}=1 / 2$ for direct allowed transitions; was fitted in to the experimental data. The optical band gap $\left(\mathrm{E}_{\mathrm{g}}\right)$ is estimated by the extrapolation of the linear portion to $(\alpha h v)^{2}=0$ in the hu versus $(\alpha h v)^{2}$ plot (fig.5). It is observed that band gap decreases from 5.8 $\mathrm{eV}$ (pristine state) to $2.28 \mathrm{eV}$ as the fluence increases which exhibits the semiconducting nature of the implanted material. Figure 6 shows variation of optical band gap with $\mathrm{N}^{+}$implantation fluence. A total fluence of $1 \times 10^{16} \mathrm{ions} / \mathrm{cm}^{2}$ resulted in a band gap around $2.28 \mathrm{eV}$ that lies in the range of a typical semiconducting material $(1-4 \mathrm{eV})$. The trend reveals the material to become increasingly conducting with fluence.

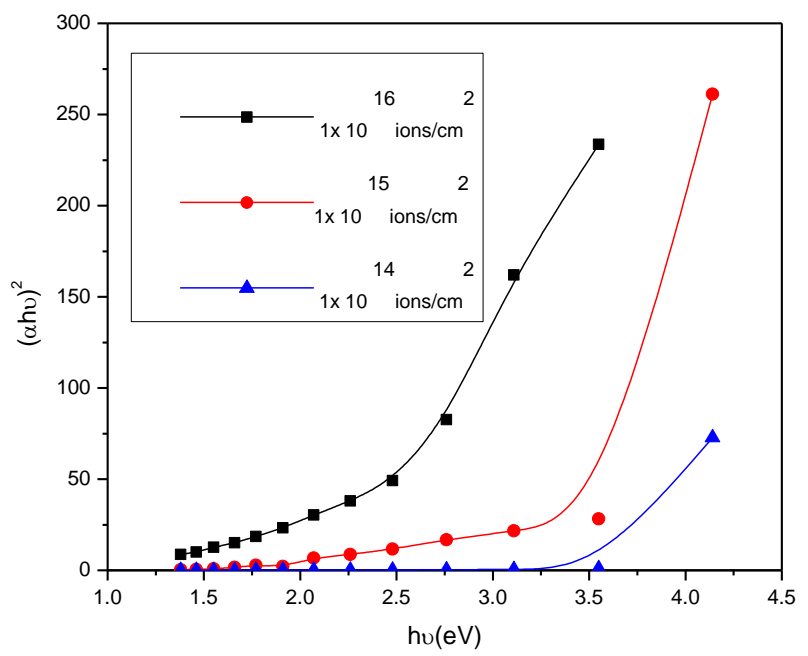

Figure 5: $(\alpha h v)^{2}$ versus photon energy for implanted films. 


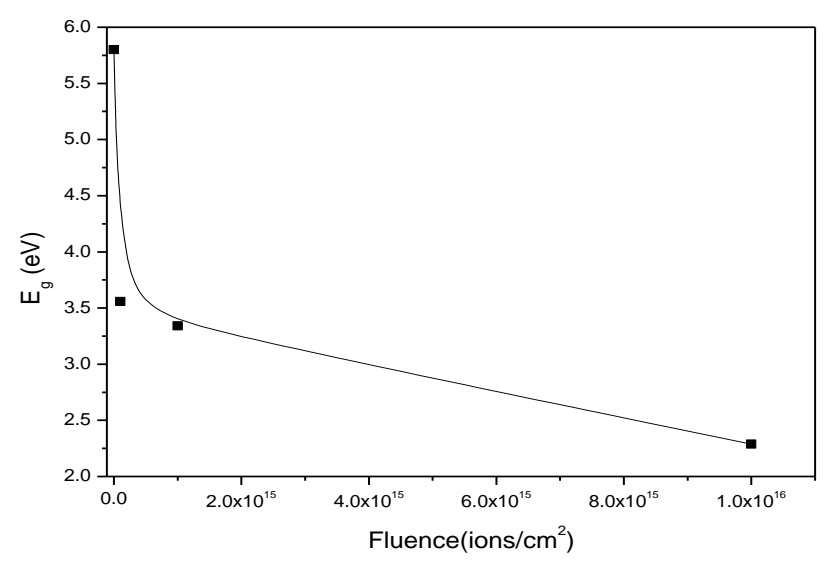

Figure 6: Variation of $\mathrm{E}_{\mathrm{g}}$ with ion fluence.

Fig. 7 \& fig. 8 show the scanning electron microscopic image of a polyisoprene films implanted, with different ion fluences i.e., $1 \times 10^{14}$ and $1 \times 10^{16}$ ions $/ \mathrm{cm}^{2}$, at room temperature. It can be seen that at low fluence i.e. $1 \times 10^{14}$ ions $/ \mathrm{cm}^{2}$, the surface appears rough owing to the presence of wrinkles. But at high fluences $\left(1 \times 10^{16}\right.$ ions $\left./ \mathrm{cm}^{2}\right)$, the minimization of roughness of the surface takes place. The wrinkles disappear and a smoothening of the surface, with small pits of size $900 \mathrm{~nm}$, is observed. This is due to the modification arising in the polyisoprene film from much closely spaced $\mathrm{N}^{+}$ion impact. Besides, in the case of iodine-doped polyisoprene (chemical doping), such a surface smoothening was reported by Scanning Electron Micrograph.

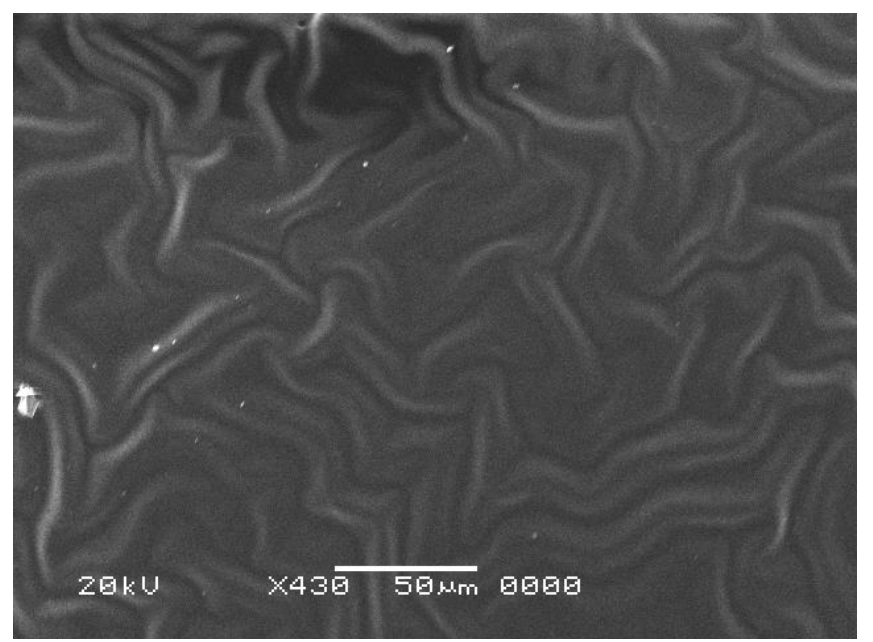

Figure 7: Scanning Electron micrograph of $\mathrm{N}^{+}$ion implanted RVNRL at a fluence of $1 \times 10^{14} \mathrm{ions} / \mathrm{cm}^{2}$ 
Figure 8: Scanning Electrom Micrograph of $\mathrm{N}^{+}$ion implanted RVNRL at a fluence of $1 \times 10^{16} \mathrm{ions} / \mathrm{cm}^{2}$

Atomic force microscopy was performed to examine the surface morphology and to measure roughness values for implanted polyisoprene samples. Fig. 9 and fig.10 show two -dimensional topographic scan of the implanted samples. The scanned area of the samples is $1 \times 1 \mu \mathrm{m}^{2}$. Figure reveals that $\mathrm{N}^{+}$ion implanted surface was smooth and uniform compared to the pristine sample surface [10]. The pristine sample has a rms $=50.042 \mathrm{~nm}[10]$. After implantation the surface structure observed at lower fluence (fig. 9 shows small domains of 200-400nm in diameter protruding out of the surface. However, at high fluences the surface appears somewhat homogeneous and the domains with 100-200nm diameter was observed. The homogeneous structure of the surface is believed to be due to the enrichment of low energy $\mathrm{N}^{+}$materials at the air-film surface. This result is consistent with other published works that report that implantation can significantly change surface morphology and smoother rough surfaces [11],[12]. Besides, Frost et. al [11] has reported a surface smoothening for InP system due to $200 \mathrm{eV}$ proton bombardment a fluence of $2 \times 10^{19}$ ions $/ \mathrm{cm}^{2}$. A.Das et.al [12] has reported that the implantation of $\mathrm{N}^{+}$ions on poly (2, 6dimethyl phenylene oxide) produced surface smoothening as a function of fluence. The rms roughness obtained for polyisoprene implanted at a fluence of $1 \times 10^{14}$ ions $/ \mathrm{cm}^{2}$ shows about $12 \mathrm{~nm}$ whereas the rms value at a fluence of $1 \times 10^{16}$ ions $/ \mathrm{cm}^{2}$ exhibited about $8 \mathrm{~nm}$. Thus it can be seen that the roughness values of the surfaces of the polyisoprene film was found to decrease upon implantation which provides a clear evidence for attainment of smoother surface as a function of fluence. Thus it can be seen that both chemical doping and implantation reduces the roughness of the surface. The three dimensional view of the implanted polyisoprene film at different fluences, illustrated in fig. 11 and fig. 12 which also indicated the presence of small domains. Thus both the chemical doping and implantation bought an evolution in chemical structure of the polymer and this leads to modification in the electrical conductivity and optical properties. However, more studies are needed to draw specific conclusions.

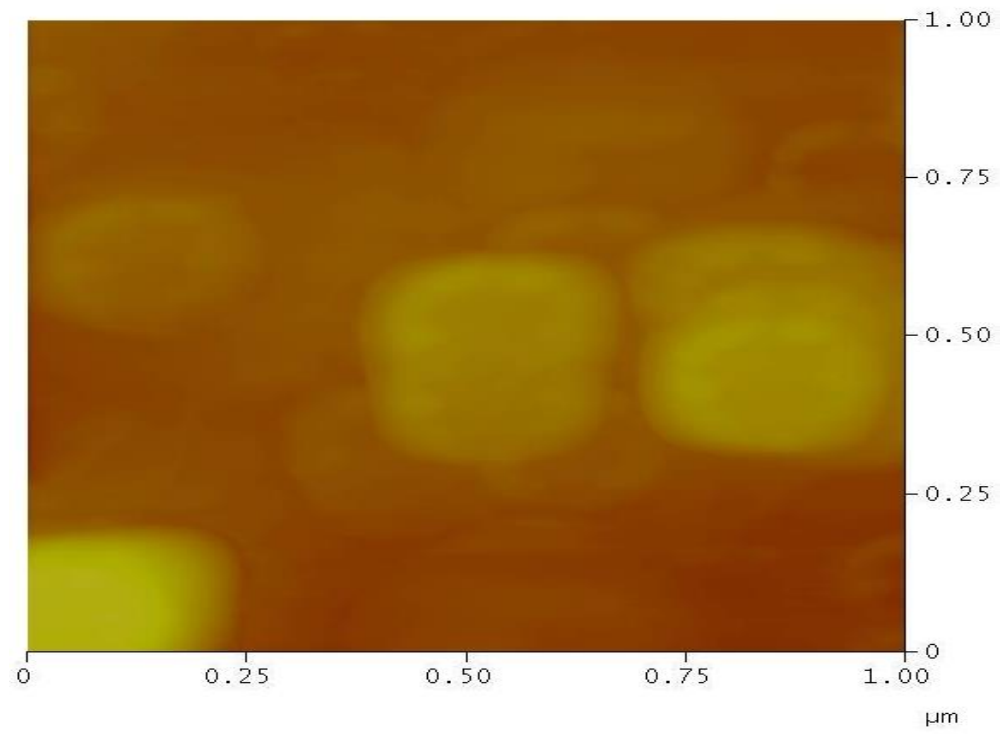


Figure 9: 1.0 X $1.0 \mu \mathrm{m}$ scan size AFM micrograph of $\mathrm{N}^{+}$ion implanted polyisoprene at a fluence of $1 \times 10^{14}$ ions $/ \mathrm{cm}^{2}$

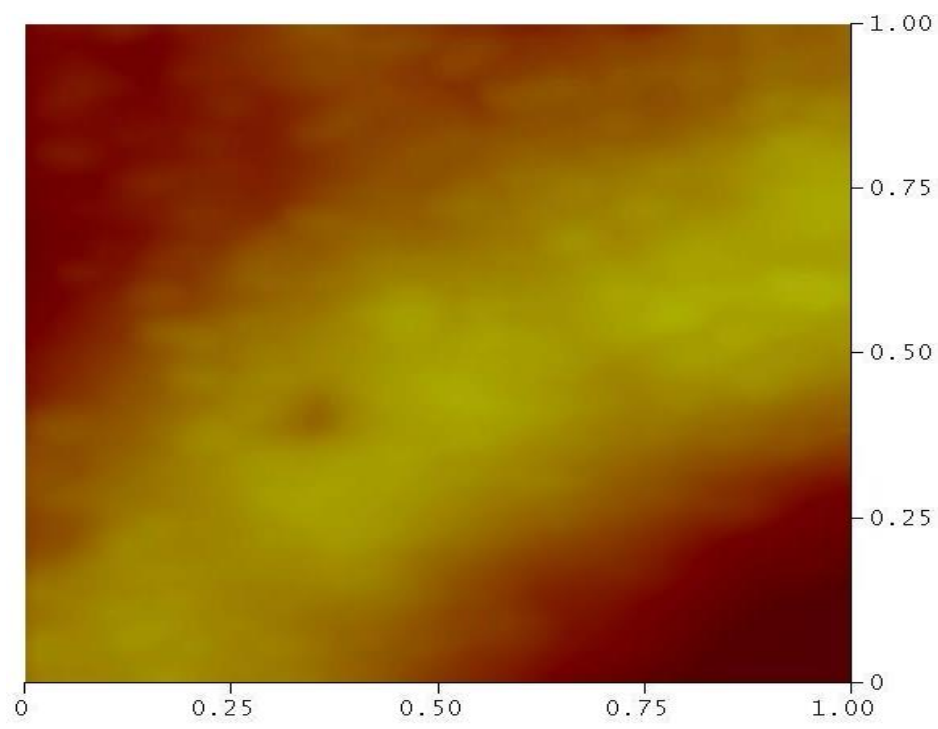

$\mu \mathrm{m}$

Figure 10: 1.0 X $1.0 \mu \mathrm{m}$ scan size AFM micrograph of $\mathrm{N}^{+}$ion implanted polyisoprene at a fluence of $1 \times 10^{16}$ ions $/ \mathrm{cm}^{2}$

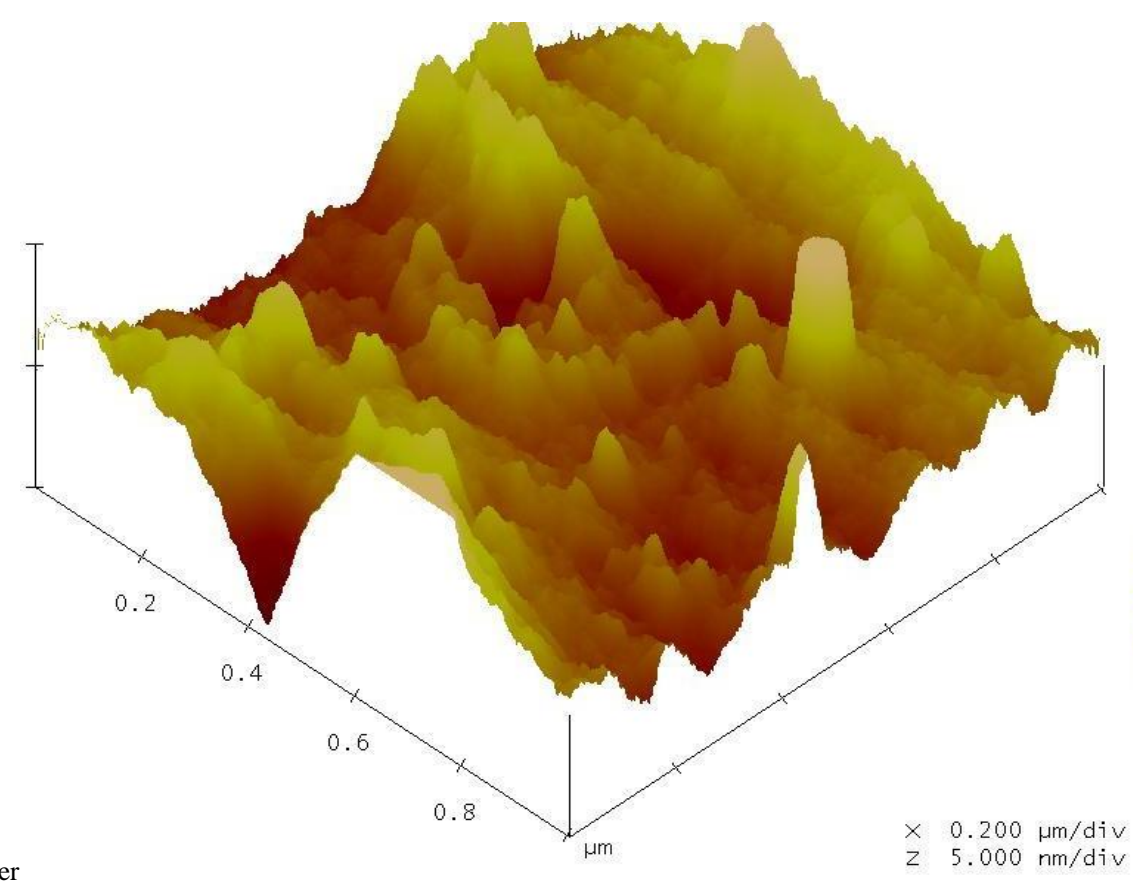


Figure 11: 3D AFM image of the $\mathrm{N}^{+}$ion implanted polyisoprene film at a fluenec of $1 \times 10^{14} \mathrm{ions} / \mathrm{cm}^{2}$

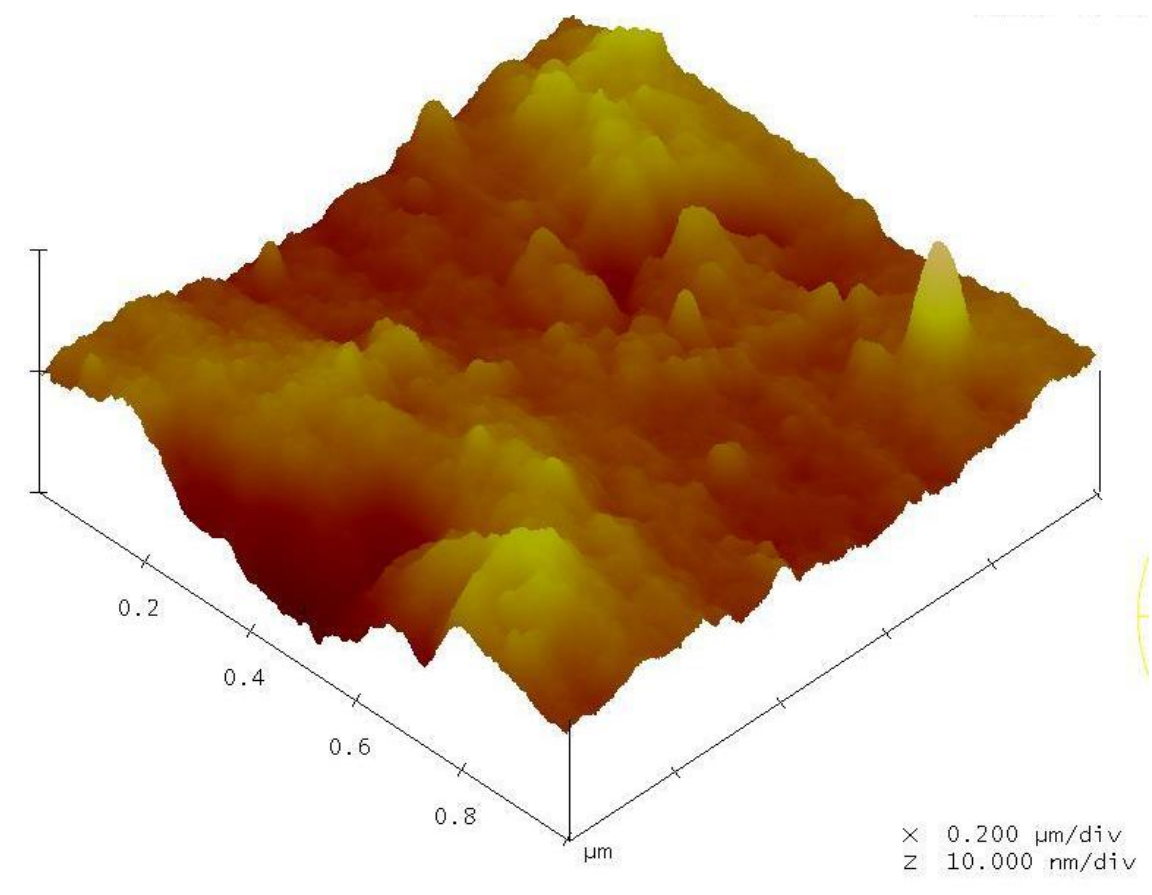

Figure 12: 3D AFM image of the $\mathrm{N}^{+}$ion implanted polyisoprene film at a fluence of $1 \times 10^{16}$ ions $/ \mathrm{cm}^{2}$

\section{IV.CONCLUSION}

$\mathrm{N}^{+}$ions implanted on Natural Rubber latex, pre-vulcanized with $\gamma$-radiation, and the changes in composition and structure of the implanted layers was investigated. The UV/Vis and FTIR spectroscopic measurements permit to follow the formation of conjugation in the course of the implantation. Evidence that useful doping can be achieved by implantation is found in the optical and morphological studies of the implanted samples.

\section{REFERENCES}

[1] L.B.Bridwell, Ion implantation of polymers for electrical conductivity enhancement, Solid State Phenomena Vol.27,Ed.Marc van Rossum. 1992,pp .163-180

[2] Y.Q.Wang, R.E.Giedd, S.S.Mohite, T.S.Jahnke, L.B.Bridwell and C.J.Sofield, Ion implantation of new polymers containing imide and amide units Material Letters, Vol.12 pp. 21-26,1991

[3] V.Svorcik,V.Rybka,I.Micek,V.Popok,O.Jankovskij,V.Hnatowicz and J.Kvitek.Structure and properties of polymers modified by ion implantation, Eur.Polym.J.Vol.30, No.12, pp1411-1415, 1994.

[4] M.Thakur, A class of Conducting polymers having non conjugated backbones.Macromolecules,Vol. 21,pp 661-664. 1998

[5] L. Dai and J. White, "Soluble conducting polymers from Polyisoprene," Polymer, vol. 32, no. 12, pp. 2120-2127, 1991.

[6] R.Sreeja, P.Pradeep, R.Alex and P.D.Sharma. Development of organic semiconductors for optoelectronic applications from prevulcanized Natural Rubber Latex.Progress in Rubber, Plastics and Recycling Technology.Vol. 20, No.3 ,187-200,2004. 
[7] P.Predeep, S.Najidha, R.Sreeja, N.S.Saxena,Surface Modification of Natural Rubber by ion implantation, Nucl.Instrum. and Meth.in Phy Res.BVol. 240, pp 850854,2005

[8] L.Dai,A.W.H.Mau,H.J.Griesser\&D.A.Winkler,Conducting polymers from polybutadiene:Molecular configuration effects on the iodine induced conjugation reactions. Macromolecules27 No. 23 , 6728-6735,1994.

[9] S.Najidha,N.S.Saxena,R.Sreeja,C.H.Unnithan and P.Predeep,Optical and electrical characterization of SbCl5 doped cis 1,4 polysisoprene. J. Material letters, Vol. 59 Pp 3431-3436,2005

[10] P.Predeep, R.Sreeja, M.Mazur and P.D.Sharma.Role of starch as a steric stabilizer for doping Natural Rubber:Effect on Optical,Electrical,Mechanical and Morphological Properties. J.Elastomers and Plastics Vol.38,pp333, 2006

[11 F.Froast, A.Schindler and F.Bigi.Ion-beam smoothing of indium-containing III-V compound semiconductors.J.Phys.A 66,pp 663-667,1998.

[12] A.Das, G.Ghosh, S.Dhara and A.Patnaik. $\mathrm{N}^{+}$beam induced nano-cluster formation in poly (2, 6-dimethyl phenylene oxide) thin films Mater. Lett. Vol. 38, pp 8286,1999

\section{AUTHORS}

First Author - Najidha.S, Department of Physics, BJM Government college,Chavara,Kollam,Kerala,India.691583

Second Author - Haidy Ignasius,Post Graduate and Research Department of Physics College of Arts and Science,Kollam,Kerala.691005.

Third Author - P. Predeep, Laboratory for Molecular Photonics and Electronics (LAMP), Department of Physics, National Institute of Technology Calicut, Kerala, India-673601

Corresponding author's email:najidhasb@gmail.com 